\title{
Familial Hypertrophic Cardiomyopathy with Wolff-Parkinson-White Syndrome Maps to a Locus on Chromosome 7q3
}

\author{
Calum A. MacRae, ${ }^{\star \ddagger}$ Nitin Ghaisas, ${ }^{5}$ Susan Kass, ${ }^{*}$ Sinead Donnelly, ${ }^{5}$ Craig T. Basson, ${ }^{1}$ Hugh C. Watkins, ${ }^{\prime \neq}$ \\ Ryuichiro Anan, * Ludwig H. Thierfelder, ' Kate McGarry, ${ }^{5}$ Edward Rowland, ${ }^{\ddagger}$ William J. McKenna, ${ }^{\ddagger}$ J. G. Seidman, * \\ and Christine E. Seidman' \\ * Department of Genetics and Howard Hughes Medical Institute, Alpert Building, Harvard Medical School, Boston, Massachusetts \\ 02115; 'Department of Cardiological Sciences, St. George’s Hospital Medical School, Cranmer Terrace, London, SW17 ORE, United \\ Kingdom; ${ }^{8}$ Our Lady's Hospital, Navan, Co Meath, Republic of Ireland; and 'Cardiology Division, Brigham and Womens Hospital \\ and Harvard Medical School, Boston, Massachusetts 02115
}

\begin{abstract}
We have mapped a disease locus for Wolff-Parkinson-White syndrome (WPW) and familial hypertrophic cardiomyopathy (FHC) segregating in a large kindred to chromosome 7 band q3. Although WPW syndrome and FHC have been observed in members of the same family in prior studies, the relationship between these two diseases has remained enigmatic. A large family with 25 surviving individuals who are affected by one or both of these conditions was studied. The disease locus is closely linked to loci D7S688, D7S505, and D7S483 (maximum two point LOD score at D7S505 was 7.80 at $\theta=0$ ). While four different FHC loci have been described this is the first locus that can be mutated to cause both WPW and/or FHC. (J. Clin. Invest. 1995. 96:12161220.) Key words: cardiomyopathy, hypertrophic - hypertrophy $\bullet$ Wolff-Parkinson-White syndrome $\bullet$ genetics $\bullet$ heart
\end{abstract}

\section{Introduction}

Wolff-Parkinson-White syndrome (WPW) ${ }^{1}$ is one of the most common congenital cardiac abnormalities with a prevalence of $0.15-3$ per 1,000 (1). WPW results from an anomalous atrioventricular (AV) conduction pathway that can produce ventricular preexcitation and paroxysmal reentrant tachycardias. The syndrome is typically recognized by a short PR interval on the surface electrocardiogram, however definitive diagnosis of preexcitation may require electrophysiologic testing. While most affected individuals appear to be sporadic, screening studies have suggested that at least $3 \%$ of probands have a symptomatic affected first degree relative (1). Reports of familial WPW have demonstrated an autosomal dominant mode of inheritance $(2-8)$.

\footnotetext{
Address correspondence to Calum MacRae, Department of Genetics, Alpert Building 524, Harvard Medical School, 200 Longwood Avenue, Boston, MA 02115. Phone: 617-432 7834; FAX: 617-432 7832; E-mail: macrae@rascal.med.harvard.edu

Received for publication 18 January 1995 and accepted in revised form 9 May 1995.
}

1. Abbreviations used in this paper: AV, atrioventricular; FHC, familial hypertrophic cardiomyopathy; LOD, logarithm of the odds; LVH, left ventricular hypertrophy; WPW, Wolff-Parkinson-White syndrome.

J. Clin. Invest.

(C) The American Society for Clinical Investigation, Inc. 0021-9738/95/09/1216/05 \$2.00

Volume 96, September 1995, 1216-1220
Familial hypertrophic cardiomyopathy (FHC) is an autosomal dominant disorder that is characterized by unexplained ventricular hypertrophy with histological evidence of myocyte and myofibrillar disarray. Genetic studies of FHC families have identified disease-causing mutations in cardiac troponin $\mathrm{T}$ on chromosome 1 (9), $\beta$ cardiac myosin heavy chain on chromosome 14 (10), and $\alpha$-tropomyosin on chromosome 15 (9). A fourth FHC locus has been described on chromosome 11 (11). There have been no reports of individuals with FHC due to mutations at these disease loci who also have WPW, although 5-10\% of hypertrophic cardiomyopathy patients have ventricular preexcitation (12). An association between these conditions was noted in the earliest descriptions of hypertrophic cardiomyopathy. In 1960 Braunwald et al. (13) proposed that abnormal ventricular activation might result in regional myocardial hypertrophy or that localized hypertrophy might disrupt normal cardiac electrical discontinuity at the atrioventricular ring.

There is clinical evidence to suggest that the development of ventricular preexcitation in individuals with FHC may be limited to particular kindreds, and may reflect a distinct genetic etiology. Affected individuals with both preexcitation and hypertrophy often exhibit high grade AV block which is usually regarded as an uncommon phenomenon in FHC (14-17). Pathologic descriptions of cardiac tissues from individuals with both disorders are also unusual in that myocardial fibrosis is the dominant histological finding (18). To elucidate the relationship between WPW and FHC we have clinically and genetically evaluated members of a large kindred with both of these conditions. Ventricular preexcitation and hypertrophic cardiomyopathy segregated as a single autosomal dominant disorder in this family. Genetic linkage analyses demonstrated that the gene defect responsible for both conditions is located on chromosome $7 \mathrm{q} 3$. These data identify the fifth FHC locus, but the first disease locus for WPW.

\section{Methods}

Clinical evaluations. All clinical and genetic studies were carried out in accordance with local institutional review committee guidelines. Surviving members of Family AS (Fig. 1) were studied by review of clinical records, history, physical exam, 12-lead electrocardiogram, and two-dimensional echocardiogram with Doppler sonography. Each individual with any abnormality detected by this evaluation was further studied by 24 h Holter monitoring. Diagnosis of individual III-22 was based on necropsy data.

FHC was diagnosed on the basis of unexplained left ventricular hypertrophy as previously described (19-21). WPW was diagnosed based on documented spontaneous ventricular preexcitation or a positive adenosine test (see below). Individuals with a PR interval $<100 \mathrm{~ms}$ plus an abnormal initial QRS vector or bundle branch block and individ- 


\section{AS Pedigree}

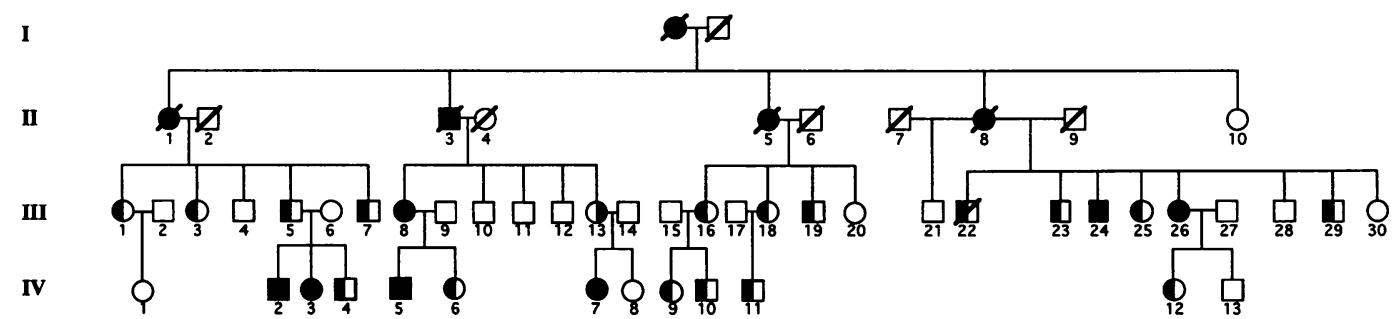

Figure 1. Family AS pedigree used for linkage analyses. Men are denoted by squares, women by circles. Affection status is indicated as follows: half-filled symbols denote FHC (left) or WPW (right); closed symbols denote both conditions; shaded symbols denote individuals with abnormal EKGs and normal echocardiograms; open symbols denote unaffected individuals.

uals with LVH plus an abnormal initial QRS vector were classified as having abnormal electrocardiographic patterns with possible preexcitation. For linkage analyses, individuals with any one of these traits were considered affected.

11 family members (Table I) had intravenous adenosine testing as described previously $(22,23)$. A rapid bolus of adenosine was administered in graded doses from 0.1 to $0.5 \mathrm{mg} / \mathrm{kg}$, with orthogonal threelead electrocardiographic monitoring, until block of physiologic atrioventricular conduction was induced or until symptoms became limiting. If electrocardiographic monitoring demonstrated increased ventricular preexcitation, the test was considered positive; if complete atrioventricular block was observed the test was considered negative. Subjects who failed to demonstrate any change in atrioventricular conduction or QRS morphology despite bradycardia, reflex tachycardia and symptoms were classified as indeterminate responders. We did not perform adenosine tests on all family members as the remaining affected individuals refused to consent to testing and we considered it unethical to administer adenosine to those who had no evidence of cardiomyopathy or preexcitation.

Genetic analyses. Peripheral blood samples obtained from each family member were used to produce Epstein-Barr virus-transformed lymphoblastoid cell lines, from which genomic DNA was isolated (19). Short tandem repeat polymorphisms from throughout the genome were amplified using the polymerase chain reaction (PCR) with published primer nucleotide sequences and analyzed by polyacrylamide gel electrophoresis as previously described (24). The genotype of individual III-22 was reconstructed based on analyses of his spouse and three children.

Linkage analyses. Two-point LOD scores (logarithm of the odds) were calculated using MLINK (version 5.1) program assuming a penetrance of 0.95 and allele frequencies from published data $(25,26)$. Multipoint LOD scores were calculated using the LINKAGE program with loci $D 7 S 483, D 7 S 505$, and $D 7 S 688$ using published map distances from the consensus map of chromosome 7 (27).

\section{Results}

Clinical evaluations. 43 surviving individuals from three generations of Family AS, were clinically evaluated (Fig. 1). None of the family members had a history of systemic hypertension. 25 family members had abnormal electrocardiograms and/or echocardiograms. These individuals had cardiac symptoms including chest pain, dyspnea, palpitations, and syncope (Table I). In addition six individuals noted skeletal muscle discomfort after exercise. Holter monitoring demonstrated a variety of dysrhythmias. Three required pacemaker insertion: two for symptomatic complete heart block (III-1, III-7) and one individual (III-3) for symptomatic sinoatrial disease.
19 individuals had echocardiographic evidence of hypertrophic cardiomyopathy (Table I and Fig. 1) with an average maximum left ventricular wall thickness (LVWT) of $20 \pm 9 \mathrm{~mm}$. This was not significantly different $(P>0.1)$ from the average LVWT of FHC patients with $\beta$ cardiac myosin heavy chain gene mutations. Postmortem examination of individual III-22 was also consistent with hypertrophic cardiomyopathy (cardiac weight $=595$ grams, histological evidence of myocyte hypertro-

Table I. Clinical Characteristics of Affected Individuals in Family AS

\begin{tabular}{|c|c|c|c|c|c|c|}
\hline $\begin{array}{c}\text { ID } \\
\text { Number }\end{array}$ & $\begin{array}{c}\text { Age/ } \\
\text { Sex }\end{array}$ & EKG & Preexcitation & LVWT & Holter & Clinical \\
\hline & & & & $m m$ & & \\
\hline III-1 & $52 / \mathrm{F}$ & PR, LVH & ND & 14 & $\mathrm{CHB}(\mathrm{V})$ & $\mathrm{C}, \mathrm{P}, \mathrm{D}, \mathrm{S}$ \\
\hline III-3 & $58 / \mathrm{F}$ & LBBB & Adenosine/IR & 26 & SB, PAF(V) & $\mathrm{C}, \mathrm{P}, \mathrm{D}, \mathbf{M}$ \\
\hline III-5 & $50 / M$ & LVH & Adenosine/IR & 20 & SB, PAF & $\mathrm{C}, \mathrm{P}, \mathrm{D}, \mathrm{S}, \mathrm{M}$ \\
\hline III-7 & $47 / M$ & LBBB & Adenosine/IR & 19 & PAF, CHB(V) & $\mathrm{D}, \mathrm{P}, \mathrm{S}$ \\
\hline III-8 & $47 / M$ & LBBB & Adenosine/IR & 11 & SB & P, D \\
\hline III-13 & $35 / F$ & PR & Adenosine/t & 12 & $\mathbf{N}$ & $\mathrm{C}, \mathrm{P}, \mathrm{D}, \mathrm{M}$ \\
\hline III-16 & $41 / F$ & LVH & ND & 30 & PAF & C, P \\
\hline III-18 & $40 / F$ & PR, LVH & ND & 35 & $\mathbf{N}$ & C, $\mathrm{S}$ \\
\hline III-19 & 39/M & LVH & ND & 30 & $\mathbf{N}$ & $\mathrm{C}, \mathrm{S}$ \\
\hline III-22 & $32 / M$ & LBBB & ND & N/A & $\mathbf{N}$ & SCD \\
\hline III-24 & $36 / M$ & LVH & ND & 15 & SB & $\mathrm{C}, \mathrm{P}, \mathrm{S}$ \\
\hline III-25 & $31 / M$ & LBBB & Adenosine/+ & 15 & SB & $\mathrm{C}, \mathbf{P}, \mathbf{M}$ \\
\hline III-26 & $33 / \mathrm{F}$ & LBBB & Adenosine/IR & 20 & SB & C, D, M \\
\hline III-27 & $37 / F$ & LBBB & + & 34 & PAF & C, P, D \\
\hline III-30 & $31 / M$ & LVH & Adenosine/IR & 13 & SB & $\mathrm{P}, \mathrm{D}, \mathrm{M}$ \\
\hline IV-2 & 23/M & PR, LVH & + & 25 & PAF & C \\
\hline IV-3 & $22 / \mathrm{F}$ & LVH & Adenosine/IR & 10 & $\mathbf{N}$ & C \\
\hline IV -4 & $12 / \mathrm{M}$ & LVH & ND & 15 & $\mathbf{N}$ & C, P, S \\
\hline IV-5 & $20 / M$ & LVH & ND & 10 & $\mathbf{N}$ & $\mathrm{C}$ \\
\hline IV-6 & 19/F & $\mathbf{N}$ & Adenosine/- & 14 & $\mathbf{N}$ & $P, D, S$ \\
\hline IV-7 & $17 / F$ & LBBB & ND & 10 & $\mathbf{N}$ & D \\
\hline IV-9 & $18 / \mathrm{F}$ & LVH & ND & 14 & $\mathbf{N}$ & A \\
\hline IV-10 & $12 / M$ & PR, LVH & ND & 15 & $\mathbf{N}$ & A \\
\hline IV-11 & $18 / M$ & LVH & ND & 45 & $\mathbf{N}$ & $\mathrm{C}$ \\
\hline IV-12 & $19 / \mathrm{F}$ & LBBB & Adenosine/- & 18 & $\mathbf{N}$ & C \\
\hline
\end{tabular}

$E K G$, electrocardiogram; $P R$, short PR $<100 \mathrm{~ms} ; L V H$, voltage criteria for left ventricular hypertrophy; $L B B B$, left bundle branch block; $N D$, not done; $I R$, indeterminate response; $L V W T$, maximum left ventricular wall thickness; $N / A$, no available; $C H B$, complete atrioventricular block; $S B$, sinus bradycardia; $P A F$, paroxysmal atrial fibrillation; $V$, permanent pacemaker inserted; $C$, chest pain; $D$, dyspnea; $M$, skeletal muscle pain after exertion; $P$, palpitations; $S$, syncope; $A$, asymptomatic. 

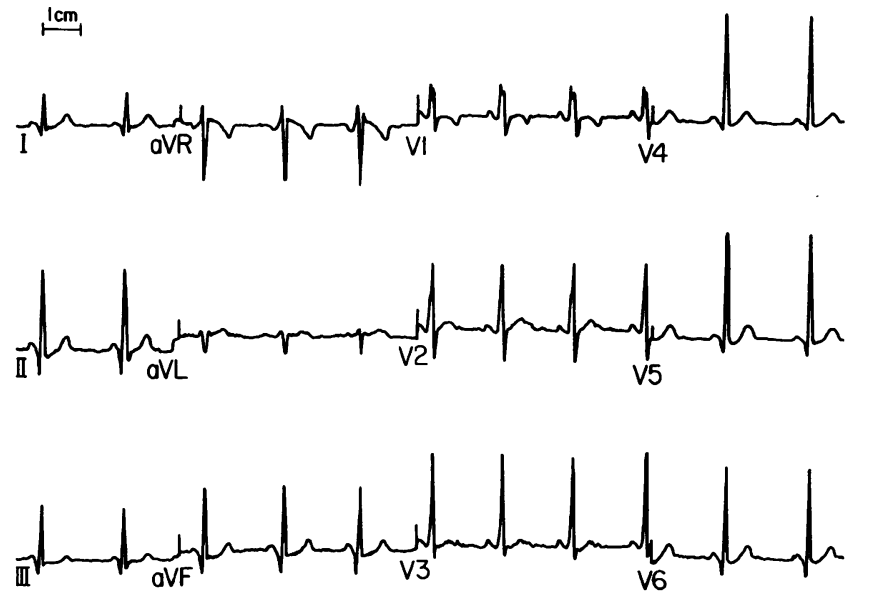

Figure 2. Electrocardiogram of individual IV-3. Note the voltage criteria for $\mathrm{LVH}$ and intraventricular conduction delay (leads $\mathrm{V}_{1}-\mathrm{V}_{3}$ ). This typified the electrocardiographic abnormalities observed in individuals IV-5 and IV-7.

phy with extensive fibrosis). The anatomical distribution of myocardial hypertrophy varied in these 20 individuals but was typical of that previously reported in FHC (28).

Two individuals (III-27 and IV-2) had previously been diagnosed with WPW based on episodic spontaneous preexcited atrial fibrillation. 17 family members had electrocardiograms suggestive of preexcitation (29) and it was possible to perform intravenous adenosine challenges (Methods) on 11 individuals. In seven individuals the test was inconclusive. In two individuals (IV-6 and IV-12) adenosine induced atrioventricular block, suggesting an anterograde accessory pathway was not present. In two individuals (III-13 and III-25) adenosine demonstrated ventricular preexcitation. Both of these individuals and individuals III-27 and IV-2 had electrocardiographic patterns suggesting right free wall accessory pathways.

Four family members with abnormal electrocardiograms (Fig. 2) had normal echocardiograms and indeterminate (III-8, IV-3) adenosine tests or refused (IV-5, IV-7) adenosine testing. Individual III-8 transmitted hypertrophic heart disease to her daughter. These individuals were considered affected for genetic analysis.

Pedigree analysis of family AS demonstrated autosomal dominant transmission of a trait that caused hypertrophic cardiomyopathy and/or WPW. This trait segregates with a high degree of penetrance but variable expressivity in this family.

Genetic analyses. DNA from all affected individuals and unaffected individuals over age $25 \mathrm{yr}$ were analyzed in linkage studies of Family AS using an autosomal dominant model of inheritance. The known FHC loci on chromosomes 14q, 1q, 11, and 15q (19-21) were initially analyzed and at each locus linkage was excluded (data not shown). We then assessed linkage between highly polymorphic loci located throughout the genome and the disease trait in Family AS. Approximately 50\% of the human genome was excluded before preliminary evidence of linkage was detected with locus D7S500, located on the distal $\mathrm{q}$ arm of chromosome 7. Linkage to nine other loci (D7S495, TCRB, D7S498, D7S688, D7S505, D7S642, D7S636, D7S483, and D7S550) was then assessed (Table II). The maximum two-point LOD score, detected with locus D7S505, was 7.80 at a recombination fraction $(\theta)$ of 0.0 indicating odds of
Table II. Pairwise Lod Scores Reflecting Linkage between Chromosome 7 Loci and Disease

\begin{tabular}{lrrrrrrr}
\hline \multicolumn{7}{c}{ Recombination fraction $(\theta)$} \\
\hline LOCUS & \multicolumn{1}{c}{0.00} & \multicolumn{1}{c}{0.01} & \multicolumn{1}{c}{0.05} & 0.10 & 0.20 & 0.30 & 0.40 \\
\hline$D 7 S 500$ & -5.29 & -3.04 & -0.74 & 0.44 & 1.16 & 1.09 & 0.58 \\
$D 7 S 495$ & -0.40 & 0.36 & 1.58 & 1.99 & 2.01 & 1.56 & 0.79 \\
$T C R B$ & -2.37 & -1.37 & 3.08 & 3.53 & 3.36 & 2.57 & 1.35 \\
$D 7 S 498$ & -1.13 & -0.77 & 0.49 & 0.94 & 0.94 & 0.61 & 0.29 \\
$D 7 S 688$ & 3.43 & 5.74 & 5.94 & 5.60 & 4.50 & 3.13 & 1.54 \\
$D 7 S 505$ & 7.80 & 7.67 & 7.14 & 6.45 & 4.94 & 3.27 & 1.47 \\
$D 7 S 642$ & 7.09 & 6.98 & 6.52 & 5.27 & 4.60 & 3.12 & 1.48 \\
$D 7 S 636$ & 6.18 & 6.08 & 5.67 & 5.13 & 3.96 & 2.64 & 1.21 \\
$D 7 S 483$ & 2.77 & 5.98 & 6.15 & 5.77 & 4.56 & 3.02 & 1.28 \\
$D 7 S 550$ & -2.80 & 1.14 & 2.76 & 3.10 & 2.82 & 2.04 & 0.97 \\
& & & & & & & \\
\hline
\end{tabular}

$>60,000,000$ to 1 that the locus responsible for disease in Family AS is on chromosome 7q3 (30). The physical location of chromosome 7 anchor marker $T C R B$ places the disease locus at $7 \mathrm{q} 35-7 \mathrm{q} 36(27)$.

To refine the location of disease a multipoint linkage map was constructed using loci D7S505, D7S688, and D7S483. A maximum multipoint LOD score of 10.2 was obtained in the interval between $D 7 S 688$ and $D 7 S 483$ (Fig. 3). Figure $3 B$ demonstrates the haplotypes of individuals who exhibited recombination across this region. The disease interval defined by these recombination events further supports the localization of the disease gene to the interval between D7S688 and D7S483, a distance of approximately seven centimorgans. Two additional families, with typical FHC (without WPW), which did not map to any of the four known FHC loci were tested with the markers $D 7 S 688$ and $D 7 S 483$ and in each case linkage was definitively excluded (data not shown).

\section{Discussion}

We report a family in which FHC and WPW are inherited as a single autosomal dominant trait and demonstrate that the disease locus maps to chromosome $7 \mathrm{q} 3$ between loci $D 7 S 688$ and D7S483. The chromosome 7 mutation in affected members of Family AS manifests as ventricular hypertrophy, ventricular preexcitation, or both. These genetic data confirm earlier hypotheses that FHC and the WPW syndrome are fundamentally related (13). Identification of the disease causing mutation in Family AS will enable a better understanding of this relationship.

Variable expressivity characterized the disorder transmitted in Family AS. 20 individuals had hypertrophic cardiomyopathy; 4 of these individuals also had WPW. One individual had WPW without cardiac hypertrophy. The actual number of Family AS members with ventricular preexcitation could not be accurately ascertained because most adenosine tests performed on these individuals were indeterminate. In several tests the apparent marked resistance of the AV node to adenosine which we observed may represent slow baseline AV nodal conduction with maximal preexcitation at rest. In view of these results and the refusal of adenosine testing by many family members, it is possible that other individuals with FHC have latent or con- 


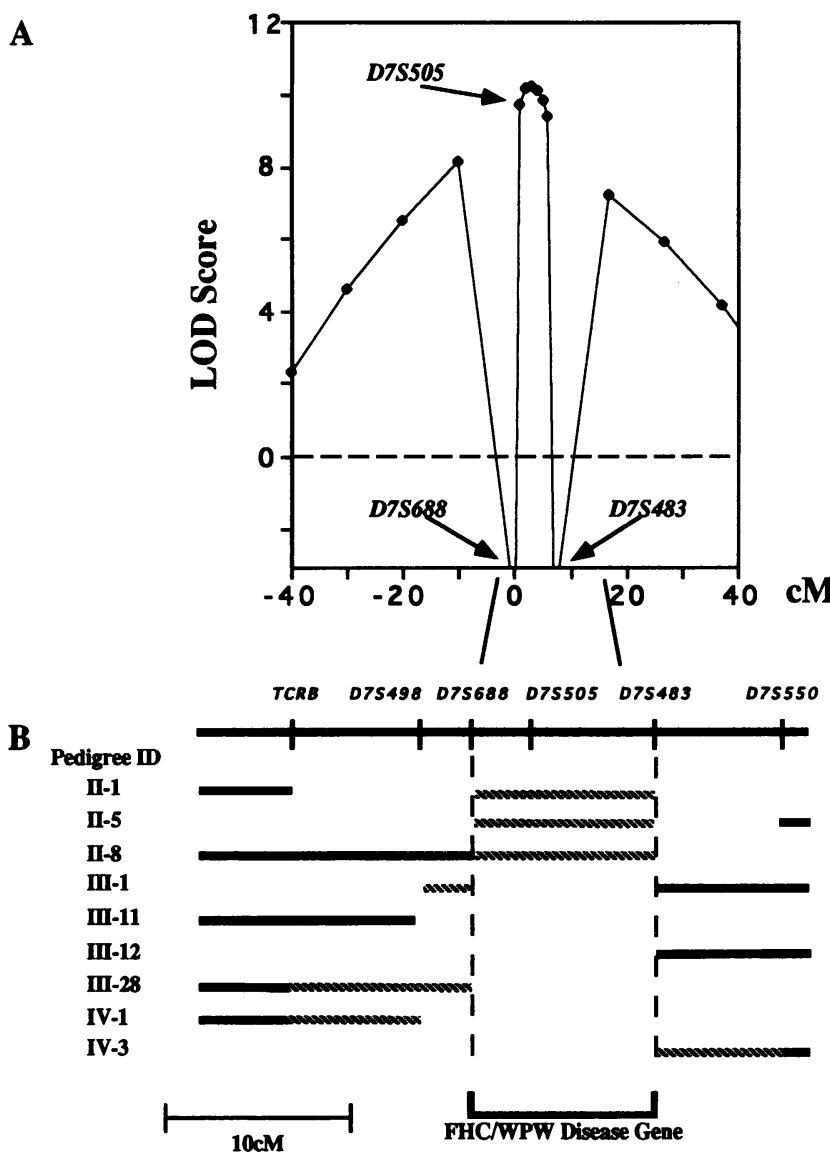

Figure 3. (A) The multipoint LOD score curve for the three markers $D 7 S 483, D 7 S 505, D 7 S 688$, and disease. The origin was arbitrarily defined as the marker $D 7 S 688$. $(B)$ The haplotypes of critical recombinants across the interval from TCRB to $D 7 S 550$. A black line represents evidence of recombination between a marker and disease. A hatched line represents non-informativeness at a given marker. Unfilled regions represent haplotypes that are concordant with disease.

cealed accessory pathways. It is also possible that individuals with normal echocardiograms may have a subclinical cardiomyopathic process which has been reported previously with WPW. Thus, much of the apparent phenotypic variation may reflect the resolution of the non-invasive diagnostic techniques used.

At present we do not know whether FHC or WPW in isolation can be due to the gene defect on chromosome 7. However, this study provides the first genetic locus for WPW and will enable investigations of familial WPW without cardiomyopathy to assess genetic heterogeneity. The clinical data on several affected members in Family AS defined a hypertrophic cardiomyopathy that is subtly different from FHC that is not accompanied by WPW. The histopathology of the myocardium from individual III-22 demonstrated marked fibrosis that was disproportionate to myocyte hypertrophy and disarray, as has been previously described primarily in individuals with ventricular preexcitation and FHC. Individuals III-1 and III-7 developed complete heart block, which is a relatively rare occurrence in FHC yet has been reported several times when WPW was also present $(16,17,31)$. While a mutation that perturbs contiguous genes at chromosome $7 q 3$ may account for both FHC and WPW in Family AS, the distinguishing features of the cardiomyopathy found in Family AS and that reported in other individuals with FHC and WPW suggest that there may be a single etiology for both conditions.

WPW is thought to arise from failed regression of developmental atrioventricular anatomical and electrical continuity (32). FHC has been demonstrated to be due to mutations in three different sarcomeric contractile proteins. Candidate genes for FHC and WPW might be expected to have a role in both processes. An actin binding protein, filamin ( FLN2) which is highly expressed in heart and skeletal muscle has been mapped to chromosome 7q (33). Given the diverse roles of actin isoforms in a variety of cell types, defects in actin-associated molecules such as filamin might produce the FHC/WPW phenotype. Two other genes encoded on chromosome $7 \mathrm{q} 3$ are also candidates for disease-causing mutations. The dominant cardiac muscarinic cholinergic receptor (CHRM2, 34) is developmentally expressed in the atrioventricular ring and myocardium. Mutations in this receptor could exert abnormal trophic effects at various stages in cardiogenesis and adult life. Similar effects might be proposed for the constitutive endothelial NO synthase $(35,36)$. We anticipate that elucidation of the defect responsible for FHC and WPW will contribute to our understanding of the mechanism relating anomalous AV pathways and ventricular hypertrophy and will offer insights into normal pathways of cardiac development.

\section{Acknowledgments}

We are indebted to the members of the AS family without whose assistance this study would have been impossible. Thanks are also due to Mohammed Miri, Annie O’Donoghue, and Shaughan Dickie for technical assistance.

These studies were supported by grants from the Howard Hughes Medical Institute (C. MacRae, S. Kass, R. Anan, J. G. Seidman, and C. E. Seidman), the British Heart Foundation (W. J. McKenna) and the American Heart Association (C. E. Seidman). C. MacRae is a Wellcome Trust (UK) Research Training Fellow. H. Watkins is a British Heart Foundation Clinician Scientist Fellow.

\section{References}

1. Vidaillet, H., J. Pressley, E. Henke, F. Harrael, and L. German. 1987. Familial occurrence of accessory atrioventricular pathways (preexcitation syndrome). N. Engl. J. Med. 317:65-69.

2. Ohnell, R. 1944. Preexcitation: a cardiac abnormality. Am. Heart J. 152(Suppl):1-167.

3. Harnifschfeger, W. 1959. Hereditary occurrence of the preexcitation (Wolff-Parkinson-White) syndrome with reentry mechanism and concealed conduction. Circulation. 19:28-40.

4. Gillette, P., D. Freed, and D. McNamara. 1978. A proposed autosomal dominant method of inheritance of the Wolff-Parkinson-White syndrome and supraventricular tachycardia. J. Pediatr. 93:257-258.

5. Schneider, R. G. 1969. Familial occurrence of Wolff-Parkinson-White syndrome. Am. Heart J. 78:34-37.

6. Chia, B. L., F. C. Yew, S. O. Chay, and A. T. Tan. 1982. Familial WolffParkinson-White syndrome. J. Electro. 15:195-198.

7. Critelli, G., J. Gallagher, W. Sealy, G. Lanza, and M. Condorelli. 1981. Morte improvisa e sindrome di preeccitazione ad incidenza familiare: resezione chirurgica delle vie anomale in due fratelli. Giornale Italione Cardiologica. 11:1883-1894.

8. Vidaillet, H. J., C. Burton, N. Ramirez, M. Gilbert, V. Behar, D. Hackel, and L. German. 1987. An unusual variant of familial preexcitation. Am. J. Card. 59:371-373.

9. Thierfelder, L., H. Watkins, C. MacRae, R. Lamas, W. McKenna, H.-P. Vosberg, J. Seidman, and C. Seidman. 1994. Alpha-tropomyosin and cardiac troponin $\mathrm{T}$ mutations cause familial hypertrophic cardiomyopathy: a disease of the sarcomere. Cell. 77:701-713.

10. Geisterfer-Lowrance, A., S. Kass, G. Tanigawa, H.-P. Vosberg, W. McKenna, C. Seidman, and J. Seidman. 1990. A molecular basis for familial hypertro- 
phic cardiomyopathy: A $\beta$ cardiac myosin heavy chain gene missense mutation. Cell. 62:999-1006.

11. Carrier, L., C. Hengstenberg, J. Beckmann, P. Guichney, C. Dufour, J. Bercovi, E. Dausse, I. Berebbi-Bertrand, C. Wisnewsky, D. Pulvenis, L. Fetler, A. Vignal, J. Weissenbach, D. Hillaire, J. Feingold, J.-B. Bouhour, A. Hagage, M. Desnos, R. Isnard, O. Dubourg, M. Komajda, and K. Schwartz. 1993. Mapping of a novel gene for familial hypertrophic cardiomyopathy to chromosome 11 . Nature Genet. 4:311-313.

12. Fananapazir, L., C. Tracey, M. Leon, J. Winkler, R. Cannon, R. Bonow, B. Maron, and S. Epstein. 1989. Electrophysiologic abnormalities in patients with hypertrophic cardiomyopathy. A consecutive analysis in 155 patients. Circulation. 80:1259-1268.

13. Braunwald, E., A. Morrow, W. Cornell, M. Aygen, and T. Hilbishi. 1960 Idiopathic hypertrophic subaortic stenosis. Clinical, hemodynamic and angiographic manifestations. Am. J. Med. 29:924-945.

14. Westlake, R., W. Cohen, and W. Willis. 1962. Wolff-Parkinson-White syndrome and familial cardiomegaly. Am. Heart J. 64:314-320.

15. Massumi, R. A. 1967. Familial Wolff-Parkinson-White syndrome with cardiomyopathy. Am. J. Med. 43:951-955.

16. Kariv, I. B. Kreisler, L. Sherf, S. Feldman, and T. Rosenthal. 1971 Familial cardiomyopathy. Am. J. Card. 28:693-706.

17. Khair, G., J. Soni, and V. Bamrah. 1985. Syncope in hypertrophic cardiomyopathy. II Coexistence of atrioventricular block and Wolff-Parkinson-White syndrome. Am. Heart J. 110:1083-1086.

18. Bharati, S., B. Strasberg, M. Bilitch, H. Salibi, W. Mandel, K. Rosen, and M. Lev. 1981. Anatomic substrate for preexcitation in idiopathic myocardial hypertrophy with fibroelastosis of the left ventricle. Am. J. Card. 48:47-58.

19. Jarcho, J. A., W. McKenna, J. A. Pare, S. D. Solomon, R. F. Holcombe, S. Dickie, T. Levi, H. Donis-Keller, J. G. Seidman, and C. E. Seidman. 1989. Mapping a gene for familial hypertrophic cardiomyopathy to chromosome 14q1. N. Engl. J. Med. 321:1372-1378.

20. Watkins, H., C. MacRae, L. Thierfelder, Y. Chou, M. Frenneaux, W. McKenna, J. G. Seidman, and C. Seidman. 1993. A disease locus for familia hypertrophic cardiomyopathy maps to chromosome 1q3. Nature Genet. 3:333337.

21. Thierfelder, L., C. MacRae, H. Watkins, J. Tomfohrde, M. Williams, W. McKenna, K. Bohm, G. Noeske, M. Schlepper, A. Bowcock, H.-P. Vosberg, J. G. Seidman, and C. Seidman. 1993. A familial hypertrophic cardiomyopathy locus maps to chromosome 15q2. Proc. Nat. Acad. Sci. USA. 90:6270-6274.

22. Cohen, T. J., K. J. Tucker, J. A. Abbott, E. H. Botvinick, E. Foster, N. B. Schiller, J. W. O'Connell, and M. M. Scheinman. 1992. Usefulness of adenosine in augmenting ventricular preexcitation for noninvasive localization of accessory pathways. Am. J. Cardiol. 69:1178-1185.
23. Garratt, C. J., A. Antoniou, M. J. Griffith, D. E. Ward, and A. J. Camm. 1990. Use of intravenous adenosine in sinus rhythm as a diagnostic test for latent preexcitation. Am. J. Cardiol. 65:868-73.

24. Chou, Y.-W., E. Brown, T. Levi, C. Crowe, B. Atkinson, H. Arnquist, G. Toss, G. Fuleihan, J. Seidman, and C. Seidman. 1992. The gene responsible for familial hypercalciuric hypercalcemia maps to chromosome $3 q$ in four unrelated families. Nature Genet. 1:295-300.

25. Charmley, P., and P. Concannon. 1993. Polymorphism and phylogeny of dinucleotide repeats in human T-cell receptor Vb6 genes. Immunogenet. 38:9297.

26. Gyapay, G., J. Morissette, A. Vignal, D. Colette, C. Fizames, P. Millasseau, S. Marc, G. Bernardi, M. Lathrop, and J. Weissenbach. 1994. The 1993-1994 Genethon human genetic linkage map. Nature Genet. 7:246-249.

27. Grzeschick, K., L. Tsui, and E. Green. 1994. Report of the first international workshop on human chromosome 7 mapping 1993. Cytogenet. Cell Genet. 65:52-73.

28. Solomon, S., S. Wolff, H. Watkins, P. Ridker, P. Come, W. McKenna, C. Seidman, and R. Lee. 1993. Left ventricular hypertrophic and morphology in familial hypertrophic cardiomyopathy associated with mutations of the beta-myosin heavy chain gene. J. A. C. C. 22:498-505

29. Perosio, A., L. Suarez, A. Bunster, A. Locreille, O. Apkarian, M. Vallazza, and R. Foye. 1983. Preexcitation syndrome and hypertrophic cardiomyopathy. $J$. Electrocard. 16:29-40.

30. Ott, J. 1992. Analysis of Human Genetic Linkage. Johns Hopkins University Press, Baltimore, MD. 302 pp.

31. Touboul, P., G. Kirkorian, G. Atallah, P. Cahen, C. De Zuloga, and P. Moleur. 1984. Atrioventricular block and preexcitation in hypertrophic cardiomyopathy. Am. J. Card. 53:961-963.

32. Anderson, R., M. Davies, and A. Becker. 1974. Atrioventricular ring specialized tissue in the normal heart. Eur. J. Cardiol. 2:219-230.

33. Gariboldi, M., E. Maestrini, F. Canzian, G. Manenti, L. De Gregorio, S. Rivella, A. Chatterjee, G. Herman, N. Archidiacono, R. Antonacci, M. Pierotti, T. Dragani, and D. Toniolo. 1994. Comparative mapping of the actin binding protein 280 genes in human and mouse. Genomics. 21:428-430.

34. Bonner, T. I., W. S. Modi, H. N. Seuanez, and S. J. O'Brien. 1991. Chromosomal mapping of five human genes encoding muscarinic acetylcholine receptors. Cytogenet. Cell Genet. 58:1850-1851.

35. Marsden, P., H. Heng, S. Scherer, R. Stewart, A. Hall, X.-M. Shi, L. Tsui, and K. Schappert. 1993. Structure and chromosomal localization of the human constitutive endothelial nitric oxide synthase gene. J. Biol. Chem. 268:1747817488.

36. Robinson, L., S. Weremowicz, C. Morton, and T. Michel. 1994. Isolation and chromosomal localization of the human endothelial nitric oxide synthase (NOS3) gene. Genomics. 19:350-357. 